\title{
Research of materials of Fe-C-Si and Fe-C-Al systems
}

\author{
Rinat Bikulov ${ }^{1, *}$ \\ ${ }^{1}$ Kazan Federal University, Naberezhnye Chelny Institute, Peace Avenue, 68/19, Naberezhnye \\ Chelne, 423812, Russian Federation
}

\begin{abstract}
The paper presents the results of a study of tests for wear resistance, thermal stability and heat resistance of materials based on Fe-C$\mathrm{Si}$ and $\mathrm{Fe}-\mathrm{C}-\mathrm{Al}$ systems (the first graphitization zone). When conducting research, a distinctive feature of obtaining materials of Fe-C-Si and Fe-C$\mathrm{Al}$ systems (the first graphitization zone) is the use of particulate of ironcontaining dispersed wastes of machine-building production. The results of the study showed the promise of using particulate wastes of mechanical engineering as charge materials for thermal stability, heat-resistant and wear-resistant castings.
\end{abstract}

\section{Wear resistance Study}

Wear phenomena are associated with very complex mechanical, thermophysical and chemical processes and depend on a large number of factors, the main of which are the atomic-molecular and structural structure of the material. In turn, an important role in the formation of the structure and the wear resistance of the material depending on it is played by the features of the technology of manufacturing the workpiece, their heat treatment. The introduction of a certain wear-resistant material composition, for example, for silicate brick molds, in conditions other than those available, should be accompanied by the study of changes in the properties of materials depending on changes in operating conditions with appropriate adjustment of the chemical composition and manufacturing technology of mold plates.

There are a large number of methods for testing samples for wear resistance [1-4], which depend on the type of wear. For the material of the plates of the molds of silicate brick, the operating mode of hydroabrasive wear is characteristic.

The wear resistance tests of materials based on the $\mathrm{Fe}-\mathrm{C}-\mathrm{Al}$ (first graphitization zone) and Fe-C-Si systems were carried out on a specially designed installation (Fig. 1). The characteristics of the installation are presented in table 1 . The chosen test method was aimed at reproducing the working conditions of the mold plates during the molding of silicate brick. The experimental setup allows testing in bulk abrasive in the presence of a corrosive environment, and without it. The samples are fixed on a rotating circle and immersed in the abrasive.

*Corresponding author : bikulov_uvr@mail.ru 


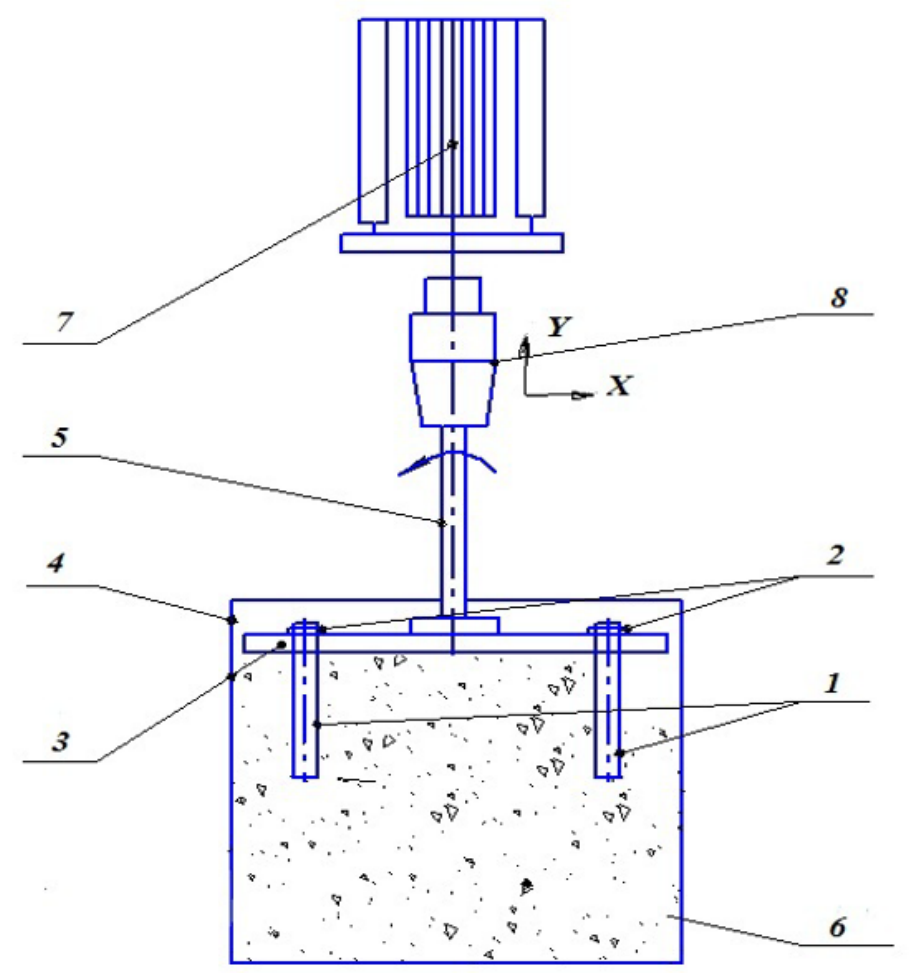

Fig. 1. Installation for determining the wear resistance of materials: 1 - samples; 2 - a nut; 3 carousel; 4 - a glass 5 - a shaft; 6 - sand; 7 - engine; 8 - cartridge.

To prevent the formation of stagnant zones, the samples are further rotated around their axis. The experimental setup allows testing in bulk abrasive in the presence of a corrosive environment, and without it. The samples are fixed on a rotating circle and immersed in the abrasive. To prevent the formation of stagnant zones, the samples are further rotated around their axis. A plate with three samples is inserted into a cylindrical drum, into which the abrasive material is poured. As the abrasive used quartz sand brand $1 \mathrm{~K} 0315 \mathrm{~A}$ and water. The ratio of quartz sand and water is 2:1.

Table 1. Installation Specifications

\begin{tabular}{|c|c|}
\hline Volume capacity & $17550 \mathrm{~mm} 3$ \\
\hline Volume of liquid medium & up to 3 l \\
\hline Central shaft speed $\left(\mathrm{W}_{1}\right)$ & $51 \mathrm{~min}^{-1}$ \\
\hline Sample rotation speed $\left(\mathrm{W}_{2}\right)$ & $217 \mathrm{~min}^{-1}$ \\
\hline The diameter of the central gear & $168 \mathrm{~mm}$ \\
\hline The diameter of the driven gear & $38 \mathrm{~mm}$ \\
\hline The linear velocity of the sample & $0.5-0.6 \mathrm{~m} / \mathrm{s}$ \\
\hline Sizes of samples & $\varnothing 23 \times 220 \mathrm{~mm}$ \\
\hline $\begin{array}{c}\text { The number of simultaneously tested } \\
\text { samples }\end{array}$ & 3 \\
\hline
\end{tabular}

The test specimens were cast into sand molds. Bars of standard size $300 \mathrm{~mm}$ cast in a sand mold, machined samples with a diameter of $23 \mathrm{~mm}$ and a length of $220 \mathrm{~mm}$. As 
reference, when tested for wear resistance, used a sample machined from rolled bar steel 20.

The test subjects and the reference samples were fixed and subjected to abrasion in the abrasive. Testing of each batch of samples lasted 10 hours. The amount of wear was determined by the loss of mass of the sample after each hour of operation, weighing on an analytical balance such as VLR-200 with an accuracy of $\pm 0.001 \mathrm{rp}$. Materials based on Fe$\mathrm{C}$-Al (first graphitization zone) and $\mathrm{Fe}-\mathrm{C}-\mathrm{Si}$ systems for samples were melted in a specialized melting unit [5]. The following materials were used in the charge according to the indicated technology: blacksmith scale, bighouse dust, iron wastes when cleaning the workpieces with a shot, and $\mathrm{FeCl}_{3}$ etched copper boards based on ferric chloride. The chemical composition of the mixture are shown in table 2.

Table 2. The chemical composition of the elements of the granular composition.

\begin{tabular}{|c|c|c|c|c|c|c|c|}
\hline \multirow{2}{*}{$\begin{array}{l}\text { The } \\
\text { chemical } \\
\text { formula } \\
\text { of the } \\
\text { component }\end{array}$} & \multicolumn{3}{|c|}{ Content,\% (mass.) } & \multirow{2}{*}{$\begin{array}{c}\text { The } \\
\text { chemical } \\
\text { formula } \\
\text { of the } \\
\text { component }\end{array}$} & \multicolumn{3}{|c|}{ Content,\% (mass.) } \\
\hline & \begin{tabular}{|c|}
$\begin{array}{c}\text { Bighouse } \\
\text { dust }\end{array}$ \\
\end{tabular} & $\begin{array}{l}\text { Forge } \\
\text { scale }\end{array}$ & $\begin{array}{l}\text { Powdered } \\
\text { iron waste }\end{array}$ & & $\begin{array}{l}\text { Bighou } \\
\text { se dust }\end{array}$ & \begin{tabular}{|l|} 
Forge \\
scale
\end{tabular} & $\begin{array}{l}\text { Powdered } \\
\text { iron waste }\end{array}$ \\
\hline 1 & 2 & 3 & 4 & 1 & 2 & 3 & 4 \\
\hline $\mathrm{FeO}$ & 11,9 & 12,1 & - & $C$ & 1,6 & - & 0,16 \\
\hline $\mathrm{Fe}_{2} \mathrm{O}_{3}$ & 59,7 & 87,1 & - & Si & - & - & 0,04 \\
\hline$F e_{\text {обш }}$ & 51,1 & 70,4 & 98,86 & $M n$ & - & - & 0,17 \\
\hline $\mathrm{MnO}$ & 1,4 & 0,6 & & $\mathrm{Cr}$ & - & - & 0,21 \\
\hline $\mathrm{Cr}_{2} \mathrm{O}_{3}$ & 0,2 & - & - & $\mathrm{Ni}$ & - & - & 0,45 \\
\hline $\mathrm{SiO}_{2}$ & 21,7 & 0,2 & - & $S$ & - & - & 0,02 \\
\hline $\mathrm{CaO}$ & 1,5 & - & - & $P$ & - & - & 0,01 \\
\hline $\mathrm{MgO}$ & 0,9 & - & - & $A 1$ & - & - & 0,02 \\
\hline $\mathrm{Al}_{2} \mathrm{O}_{3}$ & 1,1 & - & - & $T i$ & - & - & 0,06 \\
\hline
\end{tabular}

Graphite shavings and powdered lime in the amount of $0.015 \mathrm{~kg}$ and $0.064 \mathrm{~kg}$, respectively, per $1 \mathrm{~kg}$ of the mixture were also added to this mixture. The amount of liquid component in the total mass of the mixture was $40 \%$.

As liquid metal was accumulated in the melting bath, it was released into casting ladles with a capacity of $150 \mathrm{~kg}$ and a material sample was selected based on the Fe-C-Al and Fe$\mathrm{C}$-Si systems for chemical analysis. The average chemical composition of materials based on the Fe-C-Al and Fe-C-Si systems selected from 10 buckets had a content of\% (wt): C 2.5 ... 3.7\%; Si - 1.2 ... 2.0\%; S - $0.01 \ldots 0.03 \%$; P - 0.08 ... 0.1\%. The content of elements in the material based on the Fe-C-Al and Fe-C-Si systems was ensured by their presence in the granular composition and the organization of metallization processes. Materials based on the Fe-C-Al and Fe-C-Si systems were doped with $\mathrm{Si}, \mathrm{Al}, \mathrm{Cr}, \mathrm{Mn}, \mathrm{Mg}$, and $\mathrm{Ce}$. The molten material based on the $\mathrm{Fe}-\mathrm{C}-\mathrm{Al}$ and $\mathrm{Fe}-\mathrm{C}-\mathrm{Si}$ systems was cast into molds at a temperature of $1713 \mathrm{~K}$.

Nine samples were tested from each heat. With a large discrepancy between the results, the samples were retested. Relative wear resistance $\left(\mathrm{K}_{\mathrm{rs}}\right)$ was determined by the formula:

$$
K_{g s=}=\frac{\Delta P_{y z}}{\Delta P_{x}},
$$

where $\Delta$ Prs is the decrease in the mass of the standard during friction against the abrasive, 
g/hour; $\Delta$ Ps - weight reduction of the test sample, g/hour.

We studied 16 groups of different samples. When choosing the composition of materials based on Fe-C-Al and Fe-C-Si systems, economic, technological considerations, as well as thermodynamic and kinetic parameters of the structure were taken into account.

The groups of materials under study based on the Fe-C-Al and Fe-C-Si systems, their composition, graphitization coefficients are shown in table 3.

To identify the total carbide-forming and graphitizing effect of elements for each grade of materials based on the $\mathrm{Fe}-\mathrm{C}-\mathrm{Si}$ and $\mathrm{Fe}-\mathrm{C}-\mathrm{Al}$ systems, the graphitization coefficient $\mathrm{Kg}$ was determined. When determining the graphitization coefficient, we used the formula proposed by N. G. Girshovich [6]:

$$
K_{g}=C[S i-0,2(\mathrm{Mn}-1,7 S-0,3)+0,1 \mathrm{P}+0,4 \mathrm{Ni}-1,2 \mathrm{Cr}+0,5 \mathrm{Al}+0,2 \mathrm{Cu}-8 \mathrm{Mg}],
$$

where $\mathrm{C}$; $\mathrm{Si}$; $\mathrm{Mn}$; $\mathrm{S}$; $\mathrm{P}$; $\mathrm{Ni} ; \mathrm{Cr} ; \mathrm{Al} ; \mathrm{Cu}$; $\mathrm{Mg}$ is the content of elements in materials based on Fe-C-Al and Fe-C-Si systems,\%.

Table 3. Chemical composition, graphitization coefficients of the studied materials.

\begin{tabular}{|l|c|l|l|l|l|l|l|l|l|}
\hline \multirow{2}{*}{$\begin{array}{c}\text { No. } \\
\text { arr. }\end{array}$} & $\begin{array}{c}\text { Graphitizat } \\
\text { ion } \\
\text { coefficient }\end{array}$ & $\begin{array}{l}\text { C, } \\
\text { \% }\end{array}$ & Si, \% & Al, \% & $\begin{array}{l}\text { Mn, } \\
\%\end{array}$ & Cr, \% & $\begin{array}{l}\text { Mg, } \\
\%\end{array}$ & $P, \%$ & $S, \%$ \\
\hline 1 & 2,4787 & 3,5 & 1,3 & 3,5 & 1,5 & 1,5 & 0,04 & 0,08 & 0,03 \\
\hline 2 & 2,5645 & 2,5 & 1,3 & 3,5 & 1,5 & 1,5 & 0 & 0,09 & 0,02 \\
\hline 3 & 0,5222 & 3,5 & 1,4 & 2,5 & 1,5 & 1,5 & 0,06 & 0,09 & 0,03 \\
\hline 4 & $-0,033$ & 2,5 & 1,4 & 2,5 & 1,5 & 1,5 & 0,08 & 0,1 & 0,02 \\
\hline 5 & 4,2987 & 3,5 & 1,3 & 3,5 & 0,5 & 1,5 & 0 & 0,08 & 0,03 \\
\hline 6 & 3,3145 & 2,5 & 1,4 & 3,5 & 0,5 & 1,5 & 0 & 0,09 & 0,02 \\
\hline 7 & 0,5768 & 3,5 & 1,3 & 2,5 & 0,5 & 1,5 & 0,07 & 0,08 & 0,02 \\
\hline 8 & 0,4645 & 2,5 & 1,4 & 2,5 & 0,5 & 1,5 & 0,08 & 0,09 & 0,02 \\
\hline 9 & 6,7557 & 3,5 & 1,4 & 3,5 & 1,5 & 0,5 & 0,05 & 0,1 & 0,03 \\
\hline 10 & 5,8255 & 2,5 & 1,4 & 3,5 & 1,5 & 0,5 & 0 & 0,1 & 0,03 \\
\hline 11 & 6,0522 & 3,5 & 1,3 & 2,5 & 1,5 & 0,5 & 0 & 0,09 & 0,03 \\
\hline 12 & 4,5705 & 2,5 & 1,4 & 2,5 & 1,5 & 0,5 & 0 & 0,08 & 0,03 \\
\hline 13 & 7,7322 & 3,5 & 1,4 & 3,5 & 0,5 & 0,5 & 0,04 & 0,09 & 0,03 \\
\hline 14 & 6,067 & 2,5 & 1,3 & 3,5 & 0,5 & 0,5 & 0 & 0,1 & 0,02 \\
\hline 15 & 7,1057 & 3,5 & 1,4 & 2,5 & 0,5 & 0,5 & 0 & 0,1 & 0,03 \\
\hline 16 & 4,073 & 2,5 & 1,4 & 2,5 & 0,5 & 0,5 & 0,05 & 0,09 & 0,03 \\
\hline
\end{tabular}

We studied the dependence of the wear of materials based on the $\mathrm{Fe}-\mathrm{C}-\mathrm{Al}$ and $\mathrm{Fe}-$ $\mathrm{C}-\mathrm{Si}$ systems on the composition of the alloy for the main components. To determine the optimal chemical composition, a complete factor experiment $2^{4}$ was used with uniform duplication of experiments.

The following variables were selected as independent variables: the content in materials based on Fe-C-Al and Fe-C-Si systems of carbon (x1), aluminum (x2), manganese (x3), 
chromium (x4). The dependent variable was the wear of materials based on the Fe-C-Al (y) system, which was determined by the loss in mass of the sample.

The local region of determination of factors was established from a priori analysis, in particular, by the carbon potential $\pi$ c. It was decided to vary each of the factors at two levels. The intervals of variation of factors and their values on a natural scale at the main, upper and lower levels are shown in table 4. The experimental design in code and natural scales is recorded in table 5 .

Calculation of regression coefficients. In this case, you can build a model:

$$
y=b_{0}+\sum_{1 \leq i \leq 4} b_{i} x_{i}+\sum_{1 \text { sisjs4 }} b_{i j} x_{i} x_{j}+\sum_{1 \text { sisjsis4 }} b_{i j 1} x_{i} x_{j} x_{1}+b_{12 a 4} x_{1} x_{2} x_{2} x_{4}
$$

Table 4. Factor levels.

\begin{tabular}{|l|l|l|l|l|}
\hline \multicolumn{1}{|c|}{ Factors } & $x_{1}(C, \%)$ & $x_{2}(A l, \%)$ & $x_{3}(M n, \%)$ & $\begin{array}{l}x_{4} \\
(C r, \%)\end{array}$ \\
\hline Main level $\left(\mathrm{x}_{\mathrm{i} 0}\right)$ & 3 & 3 & 1 & 1 \\
\hline Variation Interval $\left(\Delta \mathrm{x}_{\mathrm{i}}\right)$ & 0,5 & 0,5 & 0,5 & 0,5 \\
\hline Upper level $\left(\mathrm{x}_{\mathrm{i}}=1\right)$ & 3,5 & 3,5 & 1,5 & 1,5 \\
\hline Lower level $\left(\mathrm{x}_{\mathrm{i}}=-1\right)$ & 2,5 & 2,5 & 0,5 & 0,5 \\
\hline
\end{tabular}

Table 5. Plan $2^{4}$ and the results of the experiments.

\begin{tabular}{|c|c|c|c|c|c|c|c|c|c|c|}
\hline \multirow{2}{*}{$\begin{array}{l}\text { No. } \\
\text { arr. }\end{array}$} & \multirow{2}{*}{$\begin{array}{l}\text { Order } \\
\text { Imple- } \\
\text { mentation }\end{array}$} & \multicolumn{4}{|c|}{ Code scale } & \multicolumn{4}{|c|}{ Natural scale } & \multirow{2}{*}{$\begin{array}{c}Y \\
\text { (wear) } \\
g r / h\end{array}$} \\
\hline & & $x_{1}$ & $x_{2}$ & $x_{3}$ & $x_{4}$ & $\begin{array}{l}X_{1} \\
C, \%\end{array}$ & $\begin{array}{l}X_{2} \\
A l, \%\end{array}$ & $\begin{array}{l}X_{3} \\
M n, \%\end{array}$ & $\begin{array}{l}X_{4} \\
C r, \%\end{array}$ & \\
\hline 1 & 2 & 3 & 4 & 5 & 6 & 7 & 8 & 9 & 10 & 11 \\
\hline 1 & 9 & + & + & + & + & 3,5 & 3,5 & 1,5 & 1,5 & 0,792 \\
\hline 2 & 2 & - & + & + & + & 2,5 & 3,5 & 1,5 & 1,5 & 0,865 \\
\hline 3 & 7 & + & - & + & + & 3,5 & 2,5 & 1,5 & 1,5 & 0,581 \\
\hline 4 & 1 & - & - & + & + & 2,5 & 2,5 & 1,5 & 1,5 & 0,652 \\
\hline 5 & 13 & + & + & - & + & 3,5 & 3,5 & 0,5 & 1,5 & 0,891 \\
\hline 6 & 14 & - & + & - & + & 2,5 & 3,5 & 0,5 & 1,5 & 0,923 \\
\hline 7 & 3 & + & - & - & + & 3,5 & 2,5 & 0,5 & 1,5 & 0,631 \\
\hline 8 & 6 & - & - & - & + & 2,5 & 2,5 & 0,5 & 1,5 & 0,724 \\
\hline 9 & 11 & + & + & + & - & 3,5 & 3,5 & 1,5 & 0,5 & 1,531 \\
\hline 10 & 16 & - & + & + & - & 2,5 & 3,5 & 1,5 & 0,5 & 1,415 \\
\hline 11 & 10 & + & - & + & - & 3,5 & 2,5 & 1,5 & 0,5 & 1,238 \\
\hline 12 & 12 & - & - & + & - & 2,5 & 2,5 & 1,5 & 0,5 & 1,156 \\
\hline 13 & 8 & + & + & - & - & 3,5 & 3,5 & 0,5 & 0,5 & 1,612 \\
\hline 14 & 4 & - & + & - & - & 2,5 & 3,5 & 0,5 & 0,5 & 1,491 \\
\hline 15 & 5 & + & - & - & - & 3,5 & 2,5 & 0,5 & 0,5 & 1,336 \\
\hline 16 & 15 & - & - & - & - & 2,5 & 2,5 & 0,5 & 0,5 & 1,285 \\
\hline
\end{tabular}

To calculate the coefficients of this model, an extended planning matrix was used. The coefficients were calculated by the formula:

$$
b_{i}=\frac{\sum_{M=1}^{\mathbb{N}} x_{i n} y_{i x}}{N}, i=0,1_{s} \ldots x,
$$

Their values were as follows: $b_{0}=1,070 ; b_{1}=0,006 ; b_{2}=0,120 ; b_{3}=-0,041 ; b_{4}=$ 0,$313 ; b_{12}=0,010 ; b_{13}=0 ; b_{14}=-0,040 ; b_{23}=0,002 ; b_{24}=-0,009 ; b_{34}=0,007 ; b_{123}=-$ 0,$006 ; b_{I 24}=-0,003 ; b_{I 34}=-0,003 ; b_{234}=-0,007 ; b_{I 234}=-0,002$. 
Coefficients whose absolute value is equal to or greater than the confidence interval should be recognized as statistically significant. In this case, it is $b_{0}, b_{1}, b_{2}, b_{3}, b_{12}, b_{14}$, $b_{24}, b_{34}, b_{123}, b_{124}, b_{134}, b_{234}$. Statistically insignificant coefficients can be excluded from the model (in this case $b_{13}, b_{23}, b_{1234}$ ).

So, after the implementation of the full factorial experiment $2^{4}$, the following regression equation is obtained:

$$
\begin{aligned}
& y=1,070+0,006 x_{1}+0,12 x_{2}-0,041 x_{2}-0,313 x_{4}+0,01 x_{1} x_{2}-0,04 x_{1} x_{4}- \\
& 0,009 x_{2} x_{4}+0,007 x_{2} x_{4}-0,006 x_{1} x_{2} x_{2}-0,003 x_{1} x_{2} x_{4}-0,007 x_{2} x_{2} x_{4}-0,003 x_{122}
\end{aligned}
$$

A brief analysis of model (5) leads to the following conclusions.

First of all, it turns out that in the studied intervals of variation of the ratio between the amount of carbon and manganese $\left(x_{1} x_{3}\right)$ and aluminum and manganese $\left(x_{2} x_{3}\right)$ in alloys does not significantly affect the wear (coefficients $b_{13}$ and $b_{23}$ are statistically insignificant). Most much wear depends on the quantity that you enter in the alloy of chromium $\left(b_{4}=|0,313|\right)$, aluminum $\left(b_{2}=|0,120|\right)$ and to a lesser degree on the amount of manganese $\left(b_{3}=|0,041|\right)$ and the ratio of carbon and chromium $\left(b_{14}=|0,040|\right)$. To increase wear resistance and reduce wear, it is necessary to increase the amount of chromium and manganese compared to the basic level (coefficients $b_{4}$ and $b_{3}$ are negative) and reduce the aluminum content (coefficient $b_{2}$ is positive).

The comparative wear resistance of materials based on Fe-C-Al and Fe-C-Si systems calculated by formula 1 is shown in table 6 .

Table 6. Comparative wear resistance of materials based on Fe-C-Al and Fe-C-Si systems.

\begin{tabular}{|c|c|c|c|c|c|c|c|}
\hline №, alloy & $\mathrm{K}_{\mathrm{rs}}$ & №, alloy & $\mathrm{K}_{\mathrm{rs}}$ & №, alloy & $\mathrm{K}_{\mathrm{rs}}$ & №, alloy & $\mathrm{K}_{\mathrm{rs}}$ \\
\hline 1 & 3,4 & 5 & 2,7 & 9 & 1,7 & 13 & 1,6 \\
\hline 2 & 3,1 & 6 & 3,06 & 10 & 2,2 & 14 & 1,8 \\
\hline 3 & 4,1 & 7 & 4,0 & 11 & 1,78 & 15 & 1,65 \\
\hline 4 & 4,7 & 8 & 4,3 & 12 & 2,3 & 16 & 2,9 \\
\hline
\end{tabular}

\section{Study of thermal stability}

One of the characteristic properties that determine the quality of billets of materials based on the Fe-C-Al system is resistance to thermal shock and prolonged exposure to nonstationary thermal loads [7]. A typical area of application of materials based on the Fe-C-Al system are metal molds.

A large number of methods for testing the thermal stability of materials based on the Fe$\mathrm{C}-\mathrm{Si}$ and Fe-C-Al systems are known [5-7]. Samples are heated in jets of hot gases, in electric resistance furnaces, in melts of metals or salts, by means of superheated steam, high-frequency currents or by direct transmission of an electric current through the sample. The criterion for selecting a heating device are the operating conditions of the part for which the material is to be used.

In this paper, the method of eddy currents of thermal stability control is used, which does not require complex equipment and excludes subjectivity in the evaluation of parameters.

When developing the design of the test facility, the requirements of maximum simplicity of its manufacture and use, unification of units, as well as the maximum possible reproducibility of experiments were taken into account. 
Thermal stability tests were performed on clamped cylindrical samples with a diameter of $8 \mathrm{~mm}$, heated by direct transmission of an electric current, in the temperature range of $293 \mathrm{~K}-1023 \mathrm{~K}$. cooling of the samples was carried out in water.

General view of the installation is shown in figure 2.

The installation includes a box base 1, on which the movable 2 and fixed 4 electrodes made of red copper are placed. A cylindrical sample of the test material is placed between the electrodes and an initial load is applied to it by means of a screw loading device fixed by a spring dynamometer 9 . The dynamometer spring is calibrated, its stiffness depends on the required initial loading. An alternating voltage of $75 \mathrm{~V}$ from the welding transformer TSD-2000 is applied to the electrodes 2 and 4 . The welding transformer as well as the water valve of the sample 5 sprayer cooling device are controlled by two highly stable time relays 6 and 7.

The control circuit of the magnetic starter of the transformer is connected to the installation via terminal block 8, and the current to the electrodes is connected by power cables 11 . Water is supplied to the sprayer device from the water supply by hose 12 . The temperature of sample 3 is recorded by MP64-02 millivoltmeter using a thermocouple gr. PR30 / 6.

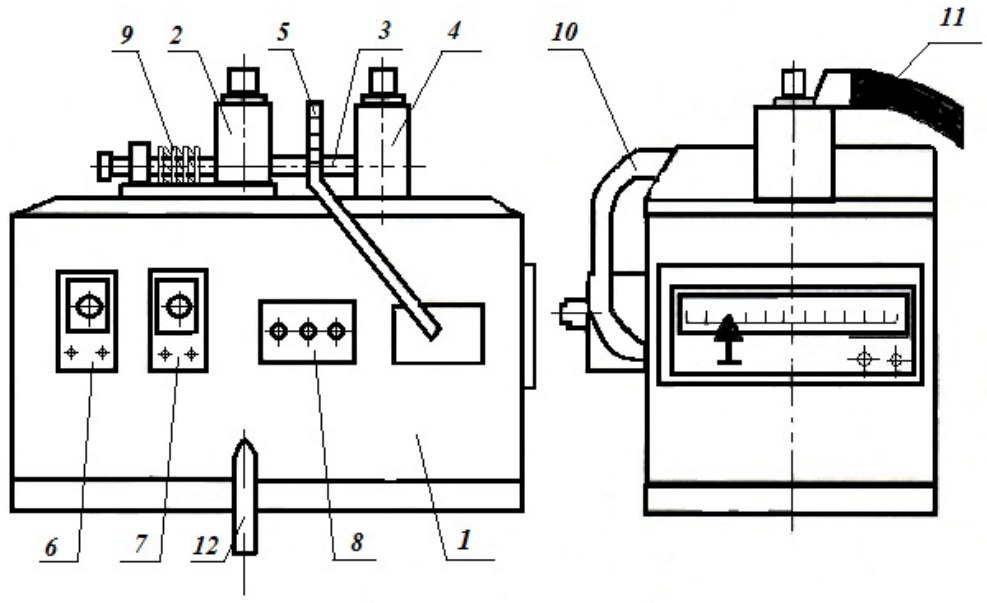

Fig. 2. - Installation of control of thermal stability of metals and alloys: 1 - Box-shaped base; 2, 4 mobile and motionless electrodes; 3 - sample; 5 - spray cooling device; 6, 7 - highly stable time relay; 9 - spring dynamometer; 10 - water supply to the spray device; 11 - power cable.

As a result of the tests, it turned out that the setting of the transformer time and current relays allows us to determine the time of heating the sample to a given temperature with sufficient accuracy $( \pm 15 \mathrm{~K})$ from the experimentally constructed diagram, Figure 3 . This made it possible to abandon further caulking of the thermocouple into the sample, which eliminated the violation of surface integrity sample and allowed to significantly simplify the measuring part of the installation.

Samples of a cylindrical shape, with a diameter of $8 \mathrm{~mm}$ and a length of $120 \mathrm{~mm}$ were machined from standard $300 \mathrm{~mm}$ siphon samples, stress concentrators were not performed.

Two test specimens were machined from each $300 \mathrm{~mm}$ bar. The first sample was subjected to thermal cycling, and the second was used as a control for differentiated analysis by the eddy current method. The test sample was heated to $1023 \mathrm{~K}$ by directly passing an electric current through it. The choice of the test temperature is due to the high prevalence of this particular value in domestic and foreign studies of the heat resistance of 
materials based on the Fe-C-Al system [8-10]. After heating and cooling the sample with running water to room temperature, the sample was removed, weighed on an analytical balance of the VLR-2000 brand with an accuracy of $0.001 \mathrm{~g}$, and placed in an eddy current sensor. The control sample was constantly in the sensor. The measurement was carried out twice, while the sample was turned over in the sensor by $180^{\circ}$, which allowed us to avoid systematic errors due to a change in the shape of the sample during thermal cycling.

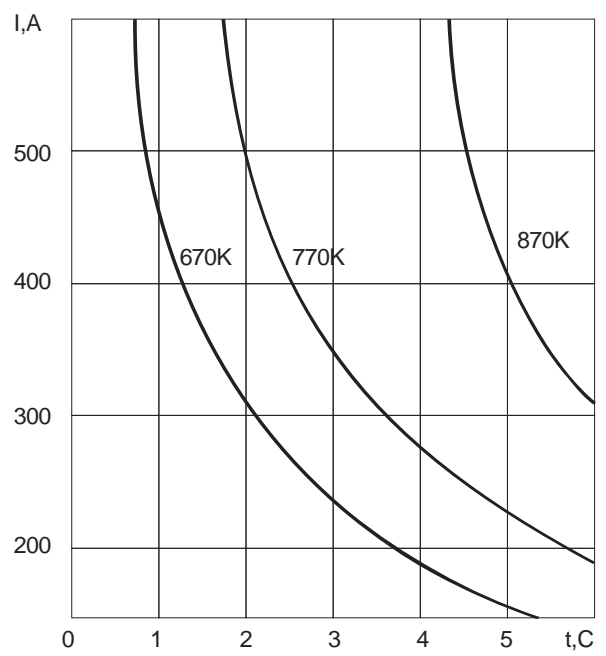

Fig. 3. Diagram for determining the heating time of the sample.

In the work, samples of the following series were investigated:

1. Materials based on the Fe-C-Si system of the 1 series (reference) - iron brand grade SCh 20 were smelted in a cupola furnace with acid lining with a productivity of $0.7 \mathrm{~kg} / \mathrm{s}$. The temperature at the chute furnace $1590 \mathrm{~K}$. Modification of materials based on the Fe - C - Si system was carried out with $0.2 \%$ FS 75 ferrosilicon in a $250 \mathrm{~kg}$ foundry ladle.

2. Materials based on the Fe-C-Al system of the 2 series - were melted in a specialized melting unit. The following materials were used in the charge according to the indicated technology: blacksmith scale, forging scale, bighouse dust, iron wastes when cleaning the workpieces with a shot, and etch of copper boards based on $\mathrm{FeCl}_{3}$ ferric chloride. The chemical composition of the mixture are given in table 2.

Graphite shavings and powdered lime in the amount of $0.015 \mathrm{~kg}$ and $0.064 \mathrm{~kg}$, respectively, per $1 \mathrm{~kg}$ of the mixture were also added to this mixture. The amount of liquid component in the total mass of the mixture was $40 \%$.

Melting of materials based on the Fe-C-Al system was carried out on a special unit, and graphite electrodes were used as a reducing agent. The consumption of pellets in a special unit is set at $7 \mathrm{~kg}$ Fe per min, the temperature of the metal and liquid slag in the smelting bath is $1873 \mathrm{~K}$, the temperature in the counterflow reactor is $1173 \mathrm{~K}$.

As liquid metal was accumulated in the melting bath, it was discharged into casting ladles with a capacity of $150 \mathrm{~kg}$ and a sample of materials based on the Fe-C-Al system was taken for chemical analysis. The average chemical composition of materials based on the Fe-C-Al system, selected from 10 ladles, had a content of\% (wt): C - 2.5 ... 3.5\%; Al - 2.5 ... 3.5\%; Si - 0.5 ... 0.8\%; S - $0.01 \ldots 0.03 \%$; P - $0.08 \ldots 0.1$. The content of elements in the material based on the $\mathrm{Fe}-\mathrm{C}-\mathrm{Al}$ system was ensured by their presence in the granular composition and the organization of metallization processes. Materials based on the $\mathrm{Fe}-\mathrm{C}$ - Al system were alloyed with $\mathrm{Al}, \mathrm{Cr}, \mathrm{Mn}$, and $\mathrm{Mg}$. The molten material based on the Fe$\mathrm{C}-\mathrm{Al}$ system was cast into molds at a temperature of $1713 \mathrm{~K}$. 
3. Materials based on the Fe-C-Al system of the 3series - were melted similarly to the materials of the AP series, but before casting into the molds they were modified with 0.3 wt.\% Cu-Mg-Ce-Ca ligature in the ladle, with a metal overheating of $1700 \mathrm{~K}$.

Due to the high complexity of the tests, we limited ourselves to an array of samples of 6 samples of each heat. Samples were taken in pairs for measurements by the differential method.

The number of thermal cycles was taken as the thermal stability until the output signal increased by an e-factor $( \pm 2.7)$. This value (the base of the natural logarithms) is taken based on the proximity of the shape of the curve of the change in the signal of the eddy current sensor at its final section to the exponential one, which makes it possible to equally fix the point of inflection of the curve, and therefore the value of the thermal stability parameter.

For the quality indicator we take the value:

$$
Q I=\frac{\mathbb{N}_{\max }-\mathbb{N}_{3 \mathrm{~min}}}{\mathbb{N}_{\mathrm{II}}},
$$

where Nmax, Nmin, Ncp - the maximum, minimum and average value of the parameter QIquality indicator. The adopted indicator takes into account the degree of instability of the properties of their average level. The lower the accepted index, the higher the stability of the properties.

Table 7. Temperature resistance of materials based on Fe-C-Si and Fe-C-Al systems

\begin{tabular}{|c|c|c|c|c|c|c|c|}
\hline Series & $\overline{N_{\mathrm{cp}}}$ & $\begin{array}{c}N_{\max }, \\
\text { cycles }\end{array}$ & $\begin{array}{c}N_{\min }, \\
\text { cycles }\end{array}$ & $\sum_{i=1}^{n}\left(N_{i}-\bar{N}\right)^{2}$ & $S^{2}$ & $S$ & $Q I$ \\
\hline 1 & 24 & 27 & 21 & 72 & 9 & 3 & 0,25 \\
\hline 2 & 52 & 63 & 41 & 968 & 121 & 11 & 0,42 \\
\hline 3 & 69 & 76 & 62 & 392 & 49 & 7 & 0,21 \\
\hline
\end{tabular}

Dispersion experience:

$$
S^{2}=\frac{1}{n-1} \times \sum_{i=1}^{n}\left(N_{i}-\bar{N}\right)^{2},
$$

where $\bar{N}$ - arithmetic mean value of thermal stability; Ni-maximum or minimum value of thermal stability; S-dispersion of experimental results.

\section{Study of heat resistance}

The weighting method (for increasing the mass of the sample), regulated by GOST 613071 , was adopted as the basis of the methodology for the comparative assessment of heat resistance.

The samples of 30x60x3 mm in size, cut from a cast plate $40 \times 40 \times 120 \mathrm{~mm}$, filled with the alloy under study, were examined. As a material for comparison, materials based on the Fe-C-Si system of the SCh20 grade were used, from blanks that had similar (compared to experimental plates) dimensions.

Each sample was placed in a corundum crucible, calcined at a temperature of $773 \pm 10$ $\mathrm{K}$ to a constant mass in an MP-42M muffle furnace.

Samples were weighed on a VRL-200 analytical balance with a crucible daily at the end of an 18-hour exposure cycle at $1173 \pm 5 \mathrm{~K}$ and a 4-hour cooling cycle of samples with 
a furnace. Then, in 2 hours, the temperature in the furnace rose to the operating temperature of the tests and the cycle was repeated.

The specified test conditions were selected based on:

- the minimum allowable test period (24 days), allowing to compile a sufficiently adequate mathematical model of the oxidation process, and to predict the further course of oxidation;

- weighing conditions under which the samples cooled to a temperature sufficient to work safely with them. However, the processes of periodic cooling practically did not worsen the results of the experiment, as evidenced by the control experiment, in which the temperature was constantly maintained at $1173 \pm 5 \mathrm{~K}$ for 24 days, and measurements were taken only before and after the tests;

- the possibility of maintenance and the need for repair of furnaces.

The gas environment in the furnace was maintained oxidative - due to the access of air into the furnace chamber through special gaps made in the furnace door.

The results of the 24-day heat resistance test of the samples are shown in table 8. The values of S and QI were calculated according to formulas 6 and 7. In the work, samples made from similar grades were studied as for the study of thermal stability.

Table 8 - Heat resistance of materials based on the Fe-C-Si and Fe-C-Al systems

\begin{tabular}{|l|l|l|l|l|l|l|l|}
\hline Series & $\overline{N_{\text {cp }}}, \mathrm{g} / \mathrm{m}^{2} \mathrm{~h}$ & $\begin{array}{l}N_{\max }, \\
\mathrm{g} / \mathrm{m}^{2} \mathrm{~h}\end{array}$ & $\begin{array}{l}N_{\text {min }}, \\
\mathrm{g} / \mathrm{m}^{2} \mathrm{~h}\end{array}$ & $\sum_{\mathrm{i}=1}^{\mathrm{g}}\left(N_{\tilde{i}}-\overline{\mathrm{N}}\right)^{2}$ & $S^{2}$ & $S$ & $Q I$ \\
\hline 1 & 38,21 & 42,14 & 34,2 & 123,55 & 15,4 & 3,93 & 0,20 \\
\hline 2 & 28,96 & 32,24 & 25,6 & 86,06 & 10,7 & 3,28 & 0,22 \\
\hline 3 & 15,91 & 17,11 & 14,7 & 11,56 & 1,44 & 1,20 & 0,15 \\
\hline
\end{tabular}

\section{Findings}

1. When determining the wear resistance of materials based on the Fe-C-Si and Fe-C$\mathrm{Al}$ systems, it was found that in the studied ranges of variation, wear most strongly depends on the amount of $\mathrm{Cr}, \mathrm{Al}$ and $\mathrm{Mn}$ introduced into the alloy. The materials based on the Fe$\mathrm{C}$-Al system with a compact form of graphite have higher wear resistance. To increase the wear resistance and reduce wear compared to the basic level, it is necessary to reduce the $\mathrm{Al}$ content to $2.5 \%$ and increase the $\mathrm{Cr}$ and $\mathrm{Mn}$ content from 1.5 to $2 \%$.

2. When determining the thermal stability of materials based on the Fe-C-Si and Fe-CAl systems using the eddy current method, it was found that the thermal stability of materials based on the Fe-C-Si and Fe-C-Al systems depends on the melting technology . The thermal stability of materials based on the Fe-C-Si system with lamellar graphite is lower than that of materials based on the $\mathrm{Fe}-\mathrm{C}-\mathrm{Al}$ system with compact graphite and averages 24 cycles. Materials based on the Fe-C-Al system with compact graphite have a more stable and increased thermal stability. Their thermal stability averages 69 cycles.

3. In the study of heat resistance, it was found that materials based on the Fe-C-Al system with compact graphite are superior in heat resistance to the reference material based on the Fe-C-Si system (SCh20 grade cast iron) by 2.4 times and accordingly have an average heat resistance of 16 and $38 \mathrm{~g} / \mathrm{m}^{2} * \mathrm{~h}$ obtained during testing according to GOST 6130-71. 


\section{References}

1. I.I. Tsypin, White wear-resistant cast irons (M .: Metallurgy, 1983.-176 p.)

2. K.E.Baranovsky, N.I.Urbanovich, I.A.Basalai, E.V.Rosenberg, Wear test of chrome cast iron in a cast state, Mining mechanics and mechanical engineering, vol. 3, pp. 63-67 (2015)

3. V.G. Shibakov, Yu.A. Sokolova, R.A. Bikulov et al., The production of composite materials and cast irons for special purposes for mechanical engineering (M.: Paleotype Publishing House, 2010. - 239 p.)

4. K.E. Baranovovsky [et al.], Wear resistance and mechanical properties of chromium cast irons, Mining mechanics and mechanical engineering, vol. 3, pp. 96-100 (2014)

5. R.A. Bikulov, N.N. Safronov, The technological process of guaranteed compact graphitization of cast irons ( Foundry worker of Russia, vol. 1, pp. 34-36 (2010)

6. N.G. Girshovich, Guide to iron casting (L .: Mechanical engineering, 1978.- 758 p.)

7. A.D. Sherman and A.A. Zhukov, Cast Iron( M.: Metallurgy, 1991. - 576 p.)

8. Yu.G. Bobro, Alloyed Cast Iron (M.: Metallurgy, 1976. -286 p.)

9. R.A. Bikulov, M.S. Kolesnikov, V.I. Astashchenko, N.N. Zapadnova, High-strength titanium cast iron of increased heat resistance and thermomechanical fatigue ( Foundry worker of Russia, vol. 8, pp.17-20 (2009)

10. R.A. Bikulov, M.S. Kolesnikov, V.I. Astashchenko, F.G. Karikh, Multi-purpose cast iron production: composition development and process control (M .: Academia, 2009. 351p.) 